\title{
Numerical Study for Optimizing Heat Transfer in High Speed Rotating Components
}

\author{
S. WITTIG, S. KIM, TH. SCHERER and I. WEISSERT*
}

Lehrstuhl und Institut für Thermische Strömungsmaschinen, Universität Karlsruhe, 76128 Karlsruhe, Germany

(Received in final form 24 March 1997)

Cooling of high speed rotating components is a typical situation found in turbomachinery as well as in automobile engines. Accurate knowledge of discharge coefficients and heat transfer of related components is essential for the high performance of the whole engine. This can be achieved by minimized cooling air flows and avoidance of hot spots. In high speed rotating clutches for example aerodynamic investigations improving heat transfer have not been considered in the past. Advanced concepts of modern plate design try to reduce thermal loads by convective cooling methods. Therefore, secondary cooling air flows have to be enhanced by an appropriate design of the rotor stator system with orifices. CFD modelling is used to improve the basic understanding of the flow field in typical geometries used in these systems.

The computational results are obtained by a 3-D-finite-volume-code based on body fitted structured grids. The Navier Stokes equations are solved by a pressure-correction method combined with the standard $\mathbf{k}-\epsilon$-turbulence model. Considering the rotation of orifices in disks or shafts, the frame of reference has to be changed to the rotating system. The flow through orifices in high speed rotating disks can be calculated with a high level of accuracy in comparison with experiments as shown in Wittig et al. [1994].

Numerical results of the flow in a high speed rotating system are presented with emphasis on geometrical variations. Calculations are carried out in order to find an optimum design in terms of position and size of the orifices in the housing. These variations induce different physical phenomena. Special consideration is directed towards the basic problems of the flow through orifices in high speed rotating disks and shafts and the flow inside rotor-stator systems. As expected, the very complex flow fields are dominated by rotational effects. In addition it is shown that differences occur between the configuration of optimized mass flow rate and the geometry with a maximum of total heat transfer. Obviously, optimization procedures are dependent on the knowledge of the local flow field and cannot be performed without advanced CFD-methods. It is demonstrated that the approach presented here is suitable for these tasks.

Keywords: Internal heat transfer, Flow in rotating disks with orifices, Numerical simulation, Rotating frame of reference, Secondary air system, Clutch

* Corresponding author. Tel.: + 721608 3634. Fax: + 721699222. 


\section{INTRODUCTION}

Cooling of thermal highly loaded components is a typical problem found in turbomachinery as well as in automotive components. As it is well known from aeroengine secondary air systems, an optimization of such cooling systems requires the knowledge of the coolant discharge and the heat transfer characteristics of various components like labyrinth seals, discs or annular gaps. A generic problem within these systems is the flow in rotating orifices. In recent years, numerous investigations have been published concerning the discharge behavior of orifices (Lichtarowicz et al. [1965], McGreehan and Schotsch [1987], Hay and Spencer [1991]). However, most of them do not take into account the effects of rotation. At the Institut für Thermische Strömungsmaschinen (ITS), University of Karlsruhe, several investigations predicting turbulent heat and mass transfer processes have been performed for complex geometries considering rotational effects (e.g. Waschka et al. [1992] and Scherer [1994]) and major interest has been focused to the discharge characteristics of rotating orifices (Wittig et al. [1994], [1995]).

As it has been pointed out in this paper, the fundamental strategy of considering rotational effects is given by the transformation of the basic equations from the stationary into a local system, i.e. a rotating frame of reference. As another application of this approach, the present paper investigates the flow and the heat transfer in a high speed rotating clutch. High thermal loads of standard clutch design can only be reduced by inner heat conduction. However, the clutch fails if the torque will not be transmitted to the gear box by a slipping overheated clutch disc located between the pressure plates. Therefore, advanced design concepts try to reduce thermal loads by convective cooling methods. It will be shown in some detail, that numerical methods as the one described in this paper, is a valuable tool for the assessment of different design concepts. However, prior to a parameter variation which has been performed in order to get some indications for an effective and reliable clutch design, the numerical procedure will be presented and analyzed.

\section{NUMERICAL PROCEDURE}

\section{Governing Equations}

The air flow through a complex three dimensional geometry is described by the Reynolds averaged Navier Stokes equations in combination with the conservation equations of mass and energy. The set of partial differential equations can be written in the form

$$
\frac{\partial\left(\rho u_{i} \Phi\right)}{\partial x_{i}}=\frac{\partial}{\partial x_{i}}\left[\Gamma_{\Phi}\left(\frac{\partial \Phi}{\partial x_{i}}\right)-\rho \overline{u_{i}^{\prime} \Phi^{\prime}}\right]+S_{\Phi}
$$

where $\Phi$ represents the three velocity components, the enthalpy and the turbulence quantities. The turbulent stresses are modeled by the Boussinesq approach (e.g. Jischa [1982]) in combination with the standard $\mathrm{k}-\epsilon$ turbulence model (Launder and Spalding [1974]) which has been used successfully in previous studies concerning the flow through stationary and rotating orifices (e.g. Wittig et al. [1994], [1995]). For the determination of the near wall velocities, the logarithmic wall function has been used. In order to deal with complex geometries, the transport equations are transformed into a general curvilinear coordinate system and discretized by the finite volume method. The advection terms are represented by a second order discretization scheme, namely the Linear Profile Scheme (LPS), combined with Physical Advection Correction terms (PAC; Raithby [1976]). Further details of the numerical code are described in Raw et al. [1989].

\section{Rotating Frame of Reference}

From a stationary point of view, the flow through rotating orifices is periodic and unsteady. 
Switching to a co-rotating frame of reference, the system is transfered to steady state conditions. However, solving the Navier Stokes equations, additional source terms including coriolis and centripetal forces have to be considered. The substantial time derivative of the rotating system (with the velocity vector $\vec{w}$ ) can be obtained from the stationary system (with the velocity vector $\vec{c}$ ) e.g. Spurk [1989]

$$
\begin{aligned}
& {\left[\frac{D \vec{w}}{D t}\right]_{\substack{\text { Rotating } \\
\text { system }}}=\left[\frac{D \vec{c}}{D t}\right]_{I}-\underset{\substack{\text { Stationary } \\
\text { system }}}{2} \underset{\substack{\text { Coriolis } \\
\text { acceleration }}}{2 \vec{w} \times \vec{\Omega} \times(\vec{\Omega} \times \vec{r})} \underset{\substack{\text { Centripetal } \\
\text { acceleration }}}{ }} \\
& -\frac{d \vec{\Omega}}{\partial t} \times \vec{x}-\vec{a} . \\
& \begin{array}{c}
\text { Unsteady } \\
\text { term }
\end{array}
\end{aligned}
$$

Eq. (2) can be simplified by assuming the rotating system as consisting of steady state conditions superimposed by a constant angular speed $\vec{\Omega}$. Finally, the additional source terms arising from rotation are given by

$$
\vec{S}_{u}=-2 \rho \vec{\Omega} \times \vec{w}-\rho \vec{\Omega} \times(\vec{\Omega} \times \vec{r}) .
$$

In the following discussion it will be shown that depending on the discretization scheme additional terms of the rotating frame of reference occur.

Regarding flow problems in rotating machinery it is preferable to use cylindrical coordinates (Fig. 1) in case of rotation around the z-axis. The velocity vector in the stationary system is given by

$$
\vec{c}=\left(\begin{array}{c}
u_{z} \\
v_{z} \\
w_{z}
\end{array}\right)_{\varphi, r, z}
$$

whereas in the rotating system it is given by

$$
\vec{w}=\left(\begin{array}{c}
u_{z}+\omega \cdot r \\
v_{z} \\
w_{z}
\end{array}\right)_{\varphi, r, z} .
$$

The discretization of a finite volume (Fig. 1) by using the Gauss divergence theorem for advection

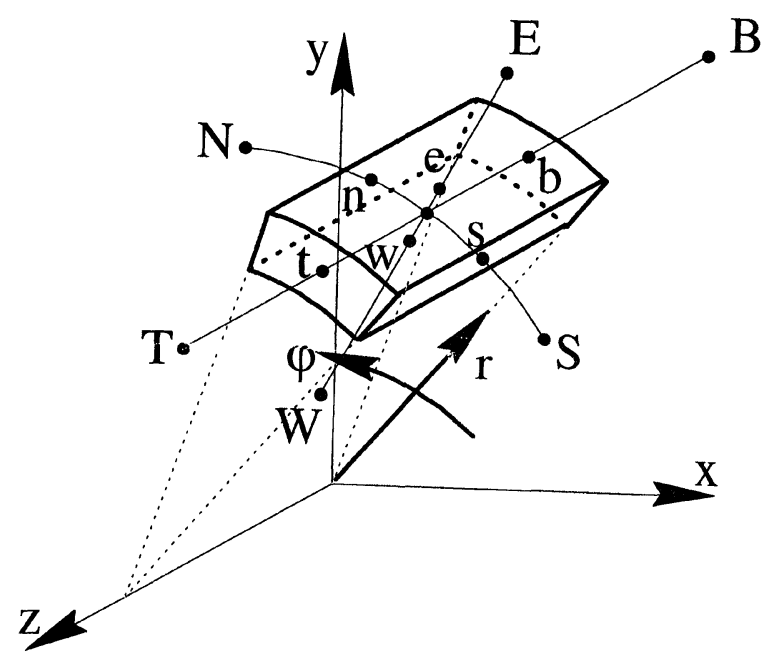

FIGURE 1 Finite volume in cylindrical coordinates.

and diffusion terms is given by

$$
\begin{aligned}
& \iiint_{V} \frac{\partial}{\partial x_{i}}\left(\rho u_{i} \Phi\right) d V=\iint_{A}\left(\rho u_{i} \Phi\right) d A \\
& \approx \rho_{e} u_{e} A_{e} \Phi_{e}-\rho_{w} u_{w} A_{w} \Phi_{w} \\
& \quad+\rho_{n} u_{n} A_{n} \Phi_{n}-\rho_{s} u_{s} A_{s} \Phi_{s} \\
& \quad+\rho_{t} u_{t} A_{t} \Phi_{t}-\rho_{b} u_{b} A_{b} \Phi_{b}
\end{aligned}
$$

and $\left(\Gamma_{\Phi}=\mu_{t}\right)$ :

$$
\begin{gathered}
\iiint_{V} \frac{\partial}{\partial x_{i}}\left(\Gamma_{\Phi} \frac{\partial \Phi}{\partial x_{i}}\right) d V=\iint_{A}\left(\Gamma_{\Phi} \frac{\partial \Phi}{\partial x_{i}}\right) d A \\
\approx \frac{\mu_{t_{e}} A_{e}}{r_{e} \Delta \varphi_{e}} \Delta \Phi_{e}-\frac{\mu_{t_{w}} A_{w}}{r_{w} \Delta \varphi_{w}} \Delta \Phi_{w}+\frac{\mu_{t_{n}} A_{n}}{\Delta r_{n}} \Delta \Phi_{n} \\
\quad-\frac{\mu_{t_{s}} A_{s}}{\Delta r_{s}} \Delta \Phi_{s}+\frac{\mu_{t_{t}} A_{t}}{\Delta r_{t}} \Delta \Phi_{t}-\frac{\mu_{t_{b}} A_{b}}{\Delta r_{b}} \Delta \Phi_{b} .
\end{gathered}
$$

It is well known that the coefficients $\Phi_{i}$ and $\Delta \Phi_{i}$ in Eq. (6) and (7) must be replaced by $\Phi$ taken from the control volume center. In order to access the impact of the discretization scheme on the transformation, two representatives for different discretization orders have been compared. As shown in Fig. 2, using UPWIND differencing for the 


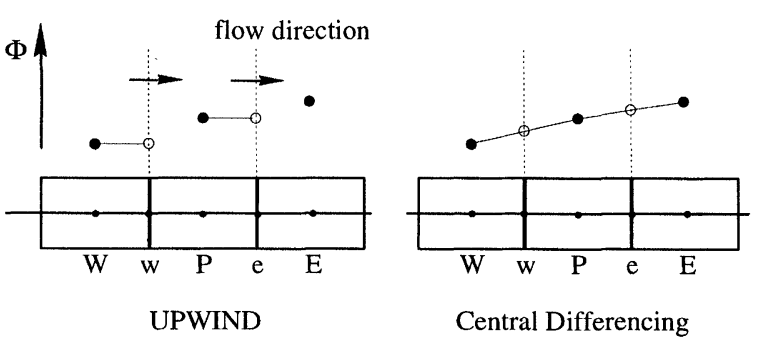

FIGURE 2 UPWIND and Central Differencing discretization scheme.

advection terms an estimation for $\Phi_{e}$ is given by

$$
\Phi_{e}=\Phi_{P}
$$

The determination of $\Delta \Phi$ using the Central Differencing Scheme follows from

$$
\Delta \Phi_{e}=\left(\Phi_{E}-\Phi_{P}\right)
$$

Inserting Eq. (8) and (9) into Eq. (2) and substituting the local velocity vector (Eq. (5)) into the left hand side and the stationary velocity vector (Eq. (4)) into the right hand side, equivalent expressions for both sides of Eq. (2) should be given. Contrary to this, additional terms, e.g. for the tangential velocity $\left(\Phi=u_{z}\right)$ like

$$
S_{u_{z}}=k_{u_{z}} \cdot \omega \cdot \Delta r
$$

are obtained. Thus, the coefficient $\Delta r$ depends on the direction of the radial velocity component. Summarizing the derivation above, it is shown that switching to a rotating frame of reference and using the UPWIND-discretization a numerical error of first order is found. This discretization error is similar to the well known problem of numerical diffusion (Patankar [1980], Noll [1993]). Thus, it is called an additional numerical diffusion. An appropriate method for its reduction, is the application of a higher order discretization scheme. The following example will show, that a dramatical decrease can be achieved, but the numerical diffusion caused by the rotation of the system cannot be avoided.
Using the Central Differencing Scheme for the advection terms an advanced estimation for $\Phi_{e}$ is found instead of Eq. (8) (Fig. 2):

$$
\Phi_{e}=\Phi_{P}+\delta \Phi_{e}
$$

The correction term $\delta \Phi_{e}$ can be obtained from

$$
\delta \Phi_{e} \approx \frac{\Delta x}{2}\left(\frac{\partial \Phi}{\partial x}\right)_{e}
$$

with

$$
\left(\frac{\partial \Phi}{\partial x}\right)_{e} \approx \frac{\left(\Phi_{E}-\Phi_{P}\right)}{\Delta x} .
$$

Therefore, the use of the Central Differencing Scheme results in a correction proportional $\left(\Phi_{E}-\right.$ $\left.\Phi_{P}\right)$. In comparison with Eq. (9) error terms can be determined, too.

A second method for reducing numerical diffusion is the adaptation of a finer mesh in order to minimize the error terms. Considering this strategy during the mesh generation, a compromise between high spatial resolution and efficiency, e.g. CPU time and memory requirement must be found.

\section{APPLICATION OF THE ROTATING FRAME OF REFERENCE}

The objective of an inner cooling system of an automotive high speed rotating clutch is a reduction of thermal loads at the pressure plates and the disc as shown in Fig. 3. In order to generate an internal flow, several orifices have been drilled into the clutch housing. It has to be pointed out that the flow pattern shown in Fig. 3 expresses the desired flow path. Any detailed information is not available and, therefore, one task of the flow simulation is given by an initial assessment of the potential for an internal flow generation as it has been envisaged by the design of the setup shown in Fig. 3. Fundamental investigations are required about the flow structure which is influenced by the flow through the orifices. Because of this, a research 
program has been performed investigating the parameters which affect the flow pattern. As a basis of the numerical study, the geometry of the Damped Flywheel Clutch (DFC) has been taken (Fig. 3).

Analogous to numerical studies performed by Wittig et al. [1995] the clutch geometry has been abstracted by a simple model. As shown in Fig. 4 the analysis of fundamental flow and heat transfer phenomena has been performed in a numerical grid consisting of three main components.

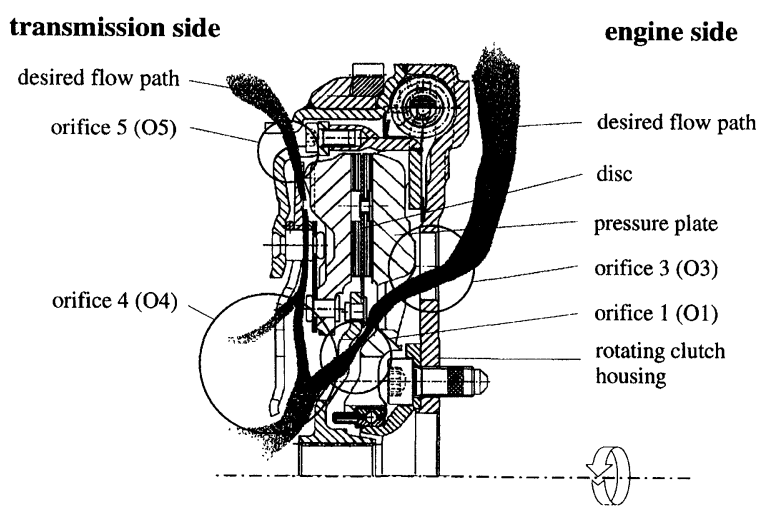

FIGURE 3 Geometry of the clutch (LuK [1994]).
- Rotating clutch disc: It consists of the pressure plates and the disc (Fig. 3). If the clutch is released, both components must be cooled by heat conduction or an internal air flow.

- Rotating clutch housing: It encloses the clutch disc and has been supplied with several orifices drilled into the housing. Influences of location and size of the orifices will be investigated with respect to improvements of the cooling air flow.

- Stationary housing: As it connects the gear box to the engine, the different sides of the clutch assembly will be referred to as transmission and engine side.

The hot section of the clutch disc (Fig. 4b) remains the same for all configurations and is set to a temperature of $T_{W, h}=200^{\circ} \mathrm{C}$. All other parts of the geometry were set to a temperature of $T_{W, c}=100^{\circ} \mathrm{C}$. Since the clutch geometry is periodic in circumferential direction, the computational area can be reduced to $1 / 8$ of the whole geometry. The circumferential areas are linked together using periodic boundary conditions. In order to avoid discretization errors a high order discretization scheme as described above has been used in combination with a mesh of $40 \times 19 \times 45$ points.

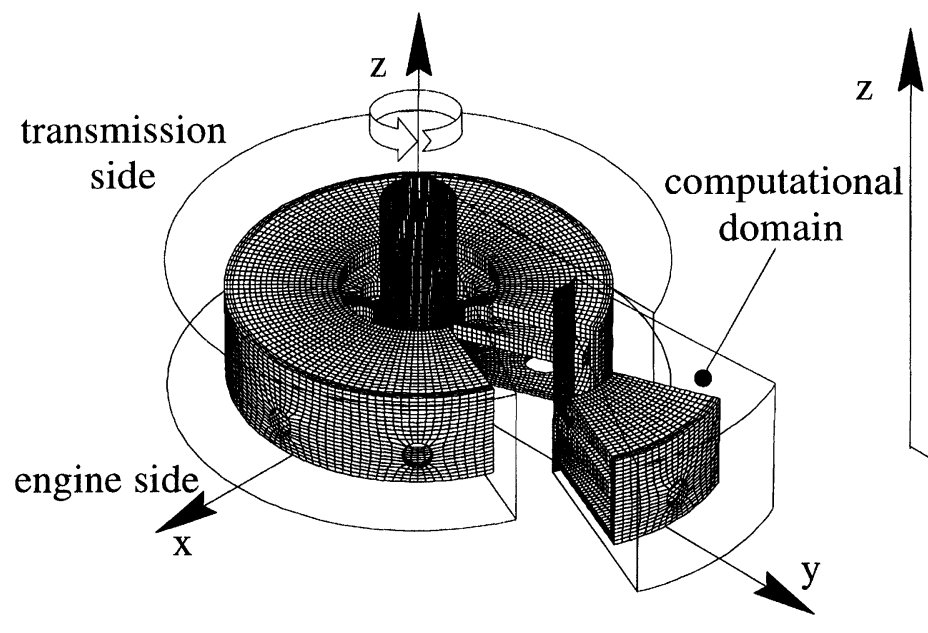

a) Ensemble model

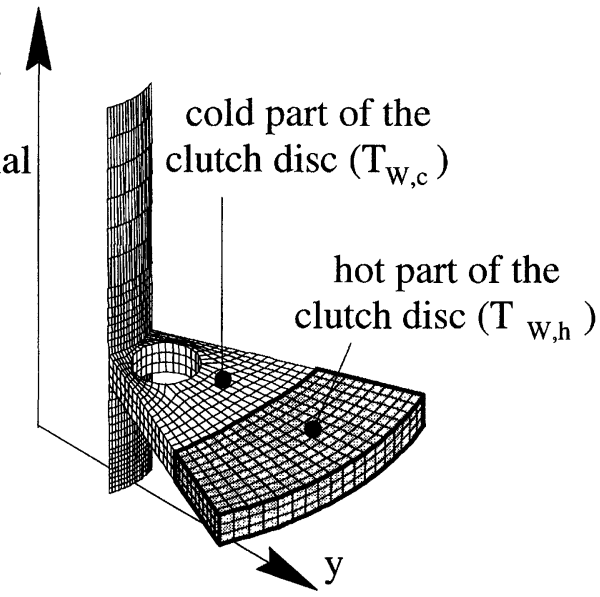

b) Clutch disc

FIGURE 4 Numerical model. 


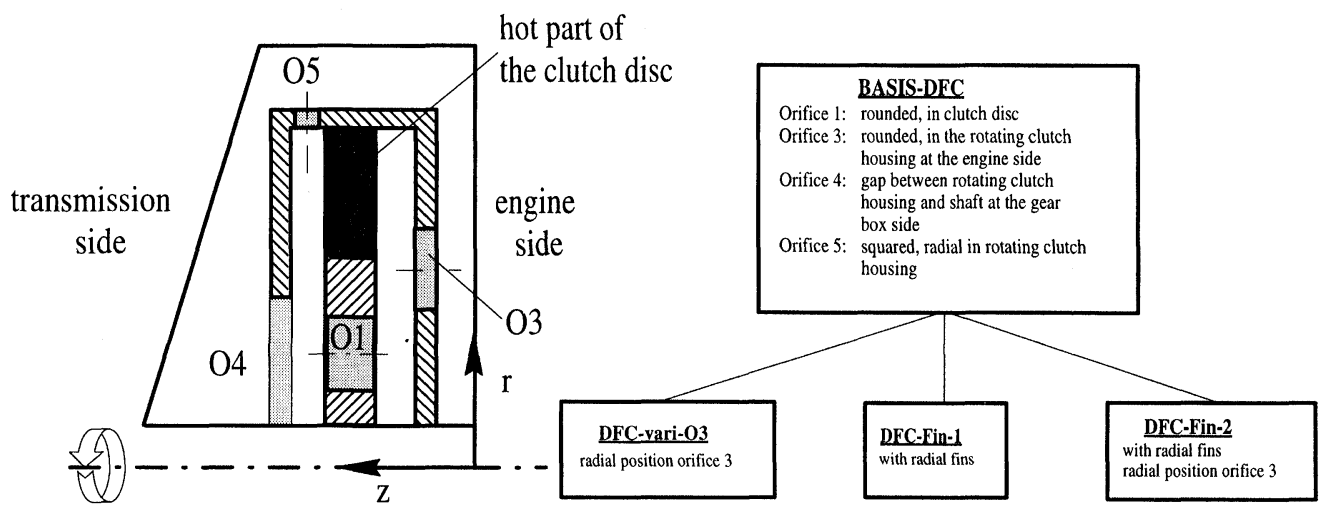

FIGURE 5 Geometry definition.

TABLE I Geometry variations

\begin{tabular}{lcccc}
\hline Configuration & Orifice $1(\mathrm{O} 1)$ & Orifice $3(\mathrm{O} 3)$ & Orifice $4(\mathrm{O} 4)$ & Orifice $5(\mathrm{O} 5)$ \\
\hline BASIS-DFC & $d=20$ & $d=28$ & $r_{i}=25$ & $\Delta z=15$ \\
& $r_{O}=40$ & $r_{O}=80$ & $r_{a}=45$ & $\Delta x=18^{\circ}$ \\
DFC-vari-O3 & $d=20$ & $d=28$ & $r_{i}=25$ & $\Delta z=15$ \\
& $r_{O}=40$ & $r_{O}=100$ & $r_{a}=45$ & $\Delta x=18^{\circ}$ \\
DFC-Fin-1 & $d=20$ & $d=28$ & $r_{i}=25$ & $\Delta z=15$ \\
& $r_{O}=40$ & $r_{O}=80$ & $r_{a}=45$ & $\Delta x=18^{\circ}$ \\
DFC-Fin-2 & $d=20$ & $d=28$ & $r_{i}=25$ & $\Delta z=15$ \\
& $r_{O}=40$ & $r_{O}=100$ & $r_{a}=45$ & $\Delta x=18^{\circ}$ \\
\hline
\end{tabular}

The configurations investigated in the present study are shown in Fig. 5 and Table I summarizes the appropriate dimensions. The entire numerical study includes numerous variations of orifice positions and sizes. In addition, the geometry of the radial orifice (O5) inside the housing has been changed from a rounded to squared shape which allows an increase of orifice area. As it will be seen in the discussion of numerical results, only the variation of the axial orifice in the housing (O3) gives a suitable effect in cooling the clutch disc. In addition, two configurations with radial fins on the transmission side of the rotating clutch housing have been studied. The main objective of this part of the investigation is the analysis of tangential acceleration effects on the flow passing through the clutch and, therefore, on the heat transfer. The fins are simulated by a wall boundary condition in tangential direction.

\section{RESULTS}

The discussion of numerical results comprises an examination of the internal clutch flow which is presented first in terms of the geometry variation defined above and, secondly, a discussion of heat transfer phenomena which are highly affected by the flow structure.

\section{Flow Structure}

As a first insight into internal clutch flows, Fig. 6 illustrates the flow between clutch housing and stationary outer housing of the basic configuration BASIS-DFC defined in Fig. 5. The flow pattern on the engine side (Fig. 6d) is similar to the flow between stationary and rotating discs discussed by Owen [1984]. In the small gap between rotor and stator the boundary layer at the stationary and at 


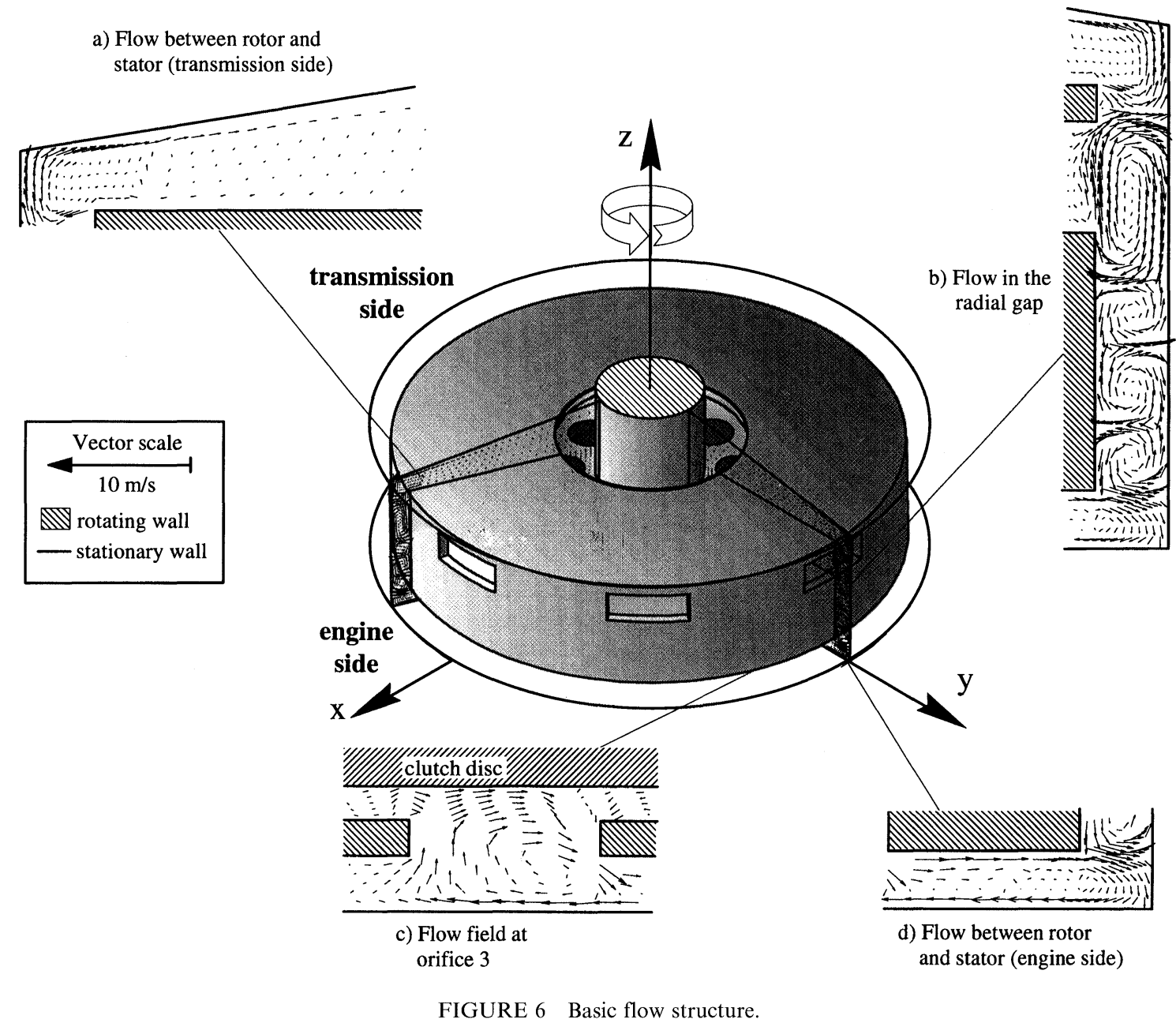

the rotating wall have different characteristics. Fluid moves radially outward near the rotating clutch housing and radially inward at the stationary outer wall. The flow pattern at $\mathrm{O} 3$, which is drilled in the rotating clutch housing at the engine side, shows an axial in- and outflow caused by a circumferential acceleration of the air (Fig. 6c). As shown in Fig. 6 b the flow structure in the radial gap is similar to a Taylor vortex flow and is very sensitive to geometric and aerodynamic variations. Therefore, the strong velocity gradients between rotating clutch housing and stationary outer housing cause a highly mixed, turbulent flow pattern in this region. In comparison with the engine side the same kind of flow structure is found at the transmission side (Fig. 6a). However, a small difference occurs due to the inclined stationary outer wall, which causes an additional deceleration of the radial inflow.

As it may have a significant influence on the heat transfer on the clutch disc, the discharge characteristics of the orifices have to be investigated. The integrated mass flux is shown in Fig. 7a for each orifice varying the geometrical parameters as defined above (Fig. 5). As it is well known, the integrated mass flux did not include the effects of recirculation zones inside orifices, i.e. amounts of local velocity caused by simultaneously in- and outflow at the orifice are much higher than the mass averaged mean velocity (Fig. 6c). Only a very 


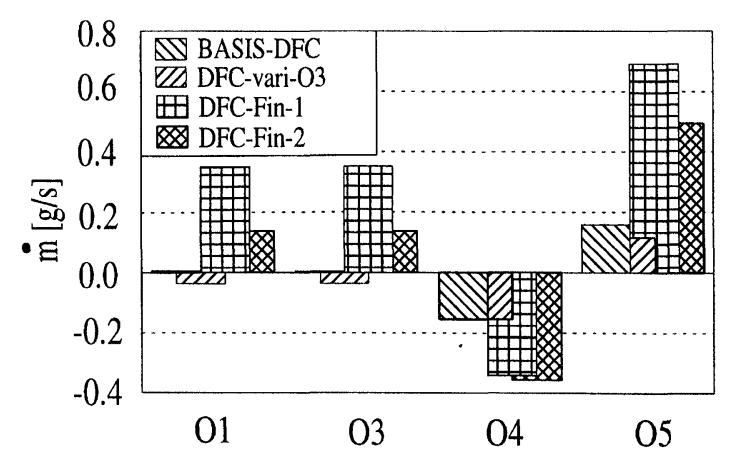

a) Mass flow through single orifices

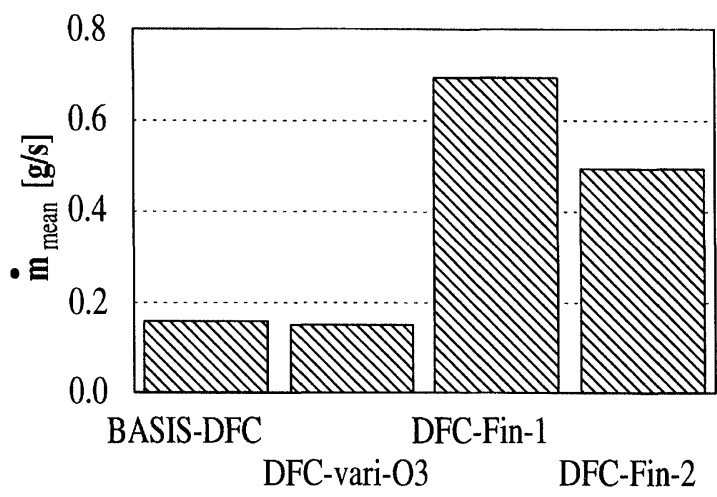

b) Main mass flow

FIGURE 7 Discharge characteristics of the clutch.

small mass flow entering the clutch is obtained for configurations without fins. Most of the air supplied by $\mathrm{O} 4$ passes the clutch in radial direction at the transmission side. The integrated mass flows through $\mathrm{O} 1$ and $\mathrm{O} 3$ show values next to zero, which indicates that a weak radial secondary flow exists at the engine side. Different locations of O3 (DFCvari-O3) have a small effect on inner mass flow. However, an increase of the turbulence level caused by the in- and outflow through $\mathrm{O} 3$ is obtained, which affects the heat transfer from the hot part of the clutch disc to the cooling air flow.

Radial fins fixed as shown in Fig. 9d cause a strong increase of convective flow at the transmission side of the clutch disc, which increases mass flow through all orifices. This is shown by an increase up to a factor of three for $\mathrm{O} 5$ and a factor of about two for O4. The air is accelerated in tangential direction where a radial pressure gradient in the rotating clutch housing is caused. The flow pattern at the engine side of the clutch disc has changed to a radial inflow, which causes an increase of the integrated mass flows through $\mathrm{O} 1$ and $\mathrm{O} 3$ (DFC-Fin-1). A decrease of the radial inflow at the engine side will be obtained, if the location of $\mathrm{O} 3$ is changed. For this case an additional radial pressure gradient in the gap between disc and rotating clutch housing reduces the air flow.
Because it gives an information about the total convection inside the clutch, all air flows passing through the orifices into the rotating clutch housing are summarized to a mean mass flow shown in Fig. 7b. This figure illustrates the strong increase of mass flows through the clutch for finned configurations. It is assumed that in comparison with the BASIS-DFC the heat transfer of this configurations will be increased, too.

\section{Heat Transfer}

The objective of the present clutch design study is to improve the heat transfer from the hot part of the clutch disc to the cooling air. In order to describe influences of geometrical variations, local as well as mean heat transfer coefficients have been determined.

$$
\begin{aligned}
\alpha_{\text {local }} & =\frac{\dot{q}}{\Delta T}, \\
\alpha_{\text {mean }} & =\frac{\int_{A} \alpha_{A i} d A}{\int_{A} d A} .
\end{aligned}
$$

Figure 8 shows the mean heat transfer coefficients (Eq. (15)) of the configurations investigated in this study. As generally, the heat transfer at the engine side of the unfinned configurations is higher 


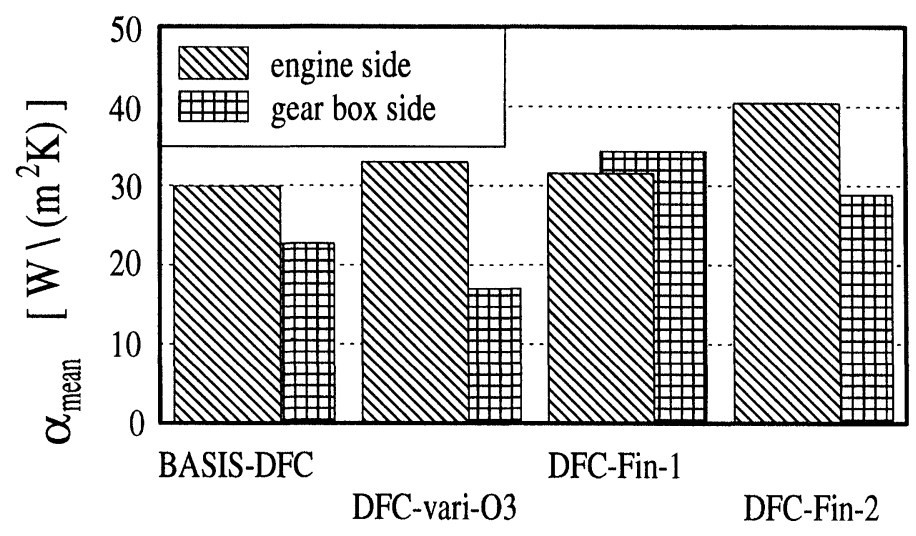

FIGURE 8 Averaged heat transfer coefficient.

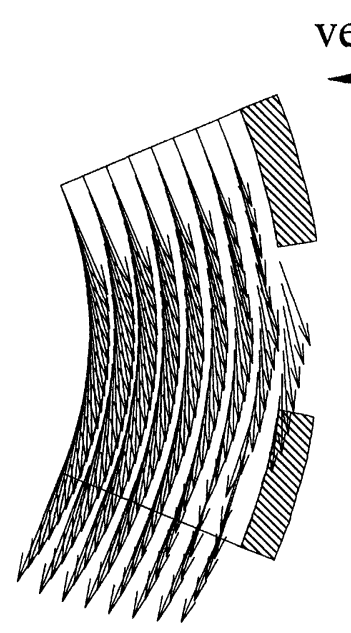

a) BASIS-DFC transmission side vector scale

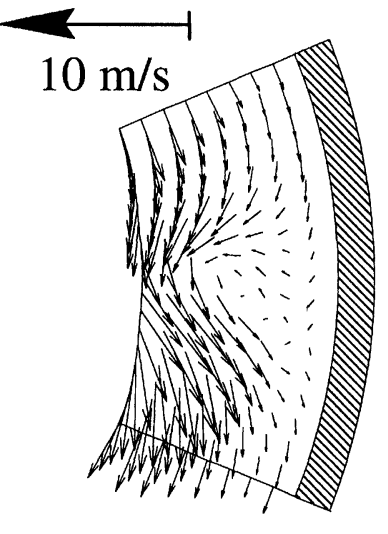

b) BASIS-DFC engine side

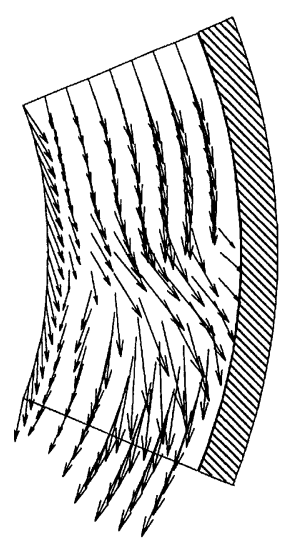

c) DFC-vari-O3 engine side

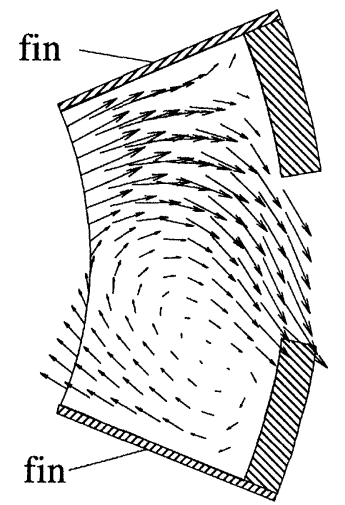

d) DFC-Fin-1 transmission side

FIGURE 9 Velocity vectors at the hot section of the clutch disc.

than the one at the transmission side. With fins, a significant increase of heat transfer coefficients at the transmission side is observed as well as at the engine side. The parameters influencing the heat transfer may be examined by the use of local heat transfer coefficients as well as local flow conditions as shown in Fig. 9 and Fig. 10.

Figure 9a shows the tangential flow pattern at the transmission side of the clutch disc. Only a small radial outflow is observed, which provides a low convective transport of the heated air in radial direction through O5. Therefore, heat transfer coefficients decrease in radial direction (Fig. 10a). At the engine side the tangential main flow direction is disturbed by the influence of O3 (Fig. 9b). The flow pattern shown in Fig. 6c reveals an inand outflow which causes a high level of turbulence. Therefore, an increase of averaged heat 


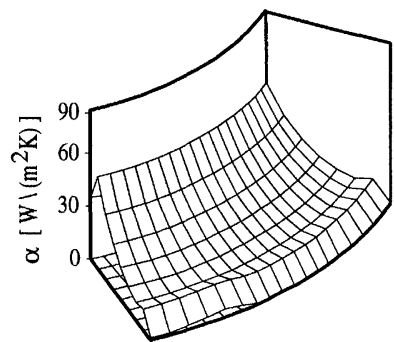

a) BASIS-DFC transmission side

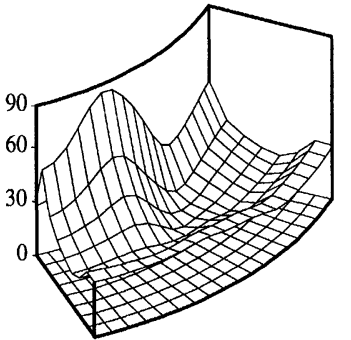

b) BASIS-DFC engine side

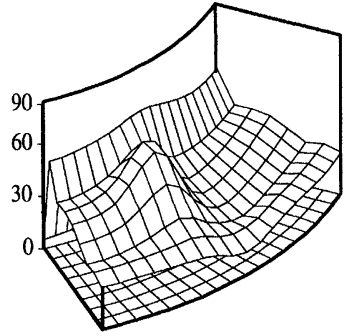

c) DFC-vari-O3 engine side

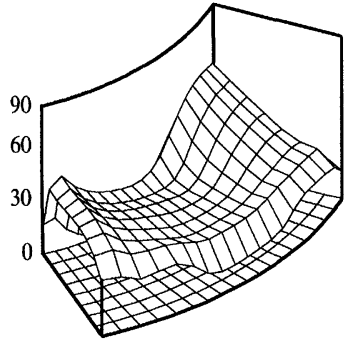

d) DFC-Fin-1 transmission side

FIGURE 10 Local heat transfer coefficients at the hot section of the clutch disc.

transfer is observed (Fig. 8). Comparing the flow pattern and the local heat transfer coefficients of Fig. 9b with Fig. 9c (Fig. 10b with Fig. 10c) it is demonstrated that the variation of the $\mathrm{O} 3$ position lead to an increase of heat flux perpendicular to the disc. This can be seen by a peak of the local heat transfer distribution shown in Fig. 10c. The flow pattern will be changed totally with a finned radial gap (Fig. 9d and 10d). The fins prevent a flow pattern in tangential direction as shown above. The radial pressure gradient induces a higher mass through flow, which leads to a strong increase of the heat transfer at the transmission side. Furthermore, a secondary flow between pressure and suction side of the finned sections causes an additional increase of local $\alpha$-numbers.

Summarizing these effects at the transmission and the engine side, the DFC-Fin-2 configuration (Table I) can be discussed exemplary, because it gives a maximum reduction of thermal loads of the clutch disc. As the dominating parameter at the transmission side a finned clutch disc which causes a high radial mass flow is favored. At the engine side the increase of turbulence caused by a high tangential velocity of $\mathrm{O} 3$ has a significant influence on the heat transfer. Discussing mean heat transfer coefficients, the decrease of $\alpha_{\text {mean }}$ at the transmission side is prevailed by the increase at the engine side. The total mass flow through the core of the clutch decreases in comparison with the configuration DFC-Fin-1.

\section{CONCLUSIONS}

A detailed investigation of effects arising from the transformation of a fixed coordinate system to a co-rotating frame of reference is presented. As a typical application, numerical results of the flow in a high speed rotating clutch are presented with emphasis on geometrical variations. Calculations are carried out in order to find an optimum design in terms of location and size of the orifices in the housing supplied for a reduction of high thermal loads in the core region of the clutch. These variations induce different physical phenomena. Special consideration is directed towards the basic problems of the flow through orifices in high speed rotating discs and shafts and the flow inside rotorstator systems. As expected, the very complex flow fields are dominated by rotational effects. In addition, it is shown that differences occur between the configuration of optimized mass flow rate and the geometry with a maximum total heat transfer. Obviously, optimization procedures depend on the knowledge of local flow fields and cannot be performed without advanced CFD-methods. It is demonstrated that the approach presented here is suitable for these tasks.

\section{Acknowledgements}

This work was supported in part by $\mathrm{LuK} \mathrm{GmbH} \mathrm{\&}$ Co Germany. Thanks are due to Dr. A. Albers, 
K. Kasper and M. Lipps of LuK GmbH for their continuous support and helpful discussions.

\section{NOMENCLATURE}

\section{Symbols}

\begin{tabular}{ll}
$A$ & $\mathrm{~m}^{2}$ \\
$\vec{c}$ & $\mathrm{~m} / \mathrm{s}$ \\
$d$ & $\mathrm{~m}$ \\
$k$ & $\mathrm{~m}^{2} / \mathrm{s}^{2}$ \\
$k_{u_{z}}$ & - \\
$\dot{m}$ & $\mathrm{~kg} / \mathrm{s}$ \\
$n$ & $1 / \mathrm{min}$ \\
$\dot{q}$ & $W / \mathrm{m}^{2}$ \\
$\varphi, r, z$ & $\bigcirc, \mathrm{m}, \mathrm{m}$ \\
$S_{\Phi}$ & - \\
$T$ & $K$ \\
$u, v, w$ & $\mathrm{~m} / \mathrm{s}$ \\
$u_{z}, v_{z}, w_{z}$ & $\mathrm{~m} / \mathrm{s}$ \\
$\vec{w}$ & $\mathrm{~m} / \mathrm{s}$ \\
$x, y, z$ & $\mathrm{~m}$ \\
$\alpha$ & $\mathrm{W} /\left(\mathrm{m}^{2} \cdot K\right)$ \\
$\Gamma$ & - \\
$\epsilon$ & $\mathrm{m} / \mathrm{s}^{3}$ \\
$\mu_{t}$ & $\mathrm{~kg} /(\mathrm{m} \cdot \mathrm{s})$ \\
$\rho$ & $\mathrm{kg} / \mathrm{m}^{3}$ \\
$\Phi$ & - \\
$\omega$ & $1 / \mathrm{s}$ \\
$\vec{\Omega}$ & $1 / \mathrm{s}$ \\
& \\
& \\
\hline &
\end{tabular}

\section{Subscripts}

$c$
$e, w, s, n, t, b$
$E, W, S, N, T, B, P$
$h$
$o$
$W$
$1,3 \ldots$

area

velocity vector

orifice diameter

turbulent kinetic energy

factor of the error term

mass flow

rotational speed

specific heat flux

cylindrical coordinates

source term

temperature

velocity components in

cartesian coordinates

velocity components in

cylindrical coordinates

local velocity vector

cartesian coordinates

heat transfer coefficient

diffusion coefficient

dissipation rate

turbulent dynamic viscosity

density

flow parameter

angular velocity

angular velocity vector

cold

surface of a finite volume center of a finite volume

hot

orifice

wall

orifice number

\section{References}

Hay, N. and Spencer, A., 1991. Discharge coefficients of cooling holes with radiused and chamfered inlets, $A S M E$ 91-GT-269.

Jischa, M., 1982. Konvektiver Impuls-, Wärme- und Stoffaustausch, F. Vieweg \& Sohn, Braunschweig/Wiesbaden.

Launder, B.E. and Spalding, D.E., 1974. The numerical computation of turbulent flows, Computer Methods in Applied Mechanics and Engineering, Vol. 3, pp. 269-289.

Lichtarowicz, A., Duggins, R.K. and Markland, E., 1965. Discharge coefficients for incompressible non-cavitating flow through long orifices, Journal Mechanical Engineering Science, Vol. 7, No. 2.

LuK GmbH \& Co., 1994. Comfort and economy, LuK drive train systems, 5. LuK Kolloquium, Bühl/Baden, pp. 32.

McGreehan, W.F. and Schotsch, M.J., 1987. Flow characteristics of long orifices with rotation and corner radiusing, ASME 87-GT-162.

Noll, B., 1993. Numerische Strömungsmechanik, Springer Verlag, Berlin Heidelberg New York.

Owen, J.M., 1984. Fluid flow and heat transfer in rotating disc systems, Heat and Mass Transfer in Rotating Machinery, Hemisphere Publishing, New York.

Patankar, S., 1980. Numerical heat transfer and fluid flow, Hemisphere Publishing, New York.

Raithby, G.D., 1976. Skew upstream differencing schemes for problems involving fluid flow, Computer Methods in Applied Mechanics and Engineering, Vol. 9, pp. 153-164.

Raw, M.J., Galpin, P.F. and Hutchinson, B.R., 1989. A Colocated Finite Volume Method for Solving the NavierStokes Equations for Incompressible and Compressible Flows in Turbomachinery: Results and Applications First Canadian Symposium on Aerospace Populsion, Ottawa Ontario, Canada.

Scherer, T., 1994. Grundlagen und Vorausetzungen der numerischen Beschreibung von Durchfluß und Wärmeübergang in rotierenden Labyrinthdichtungen, Dissertation, Universität Karlsruhe, Lehrstuhl und Institut für Thermische Strömungsmaschinen.

Spurk, J.H., 1989. Strömungslehre, Springer Verlag, Berlin Heidelberg New York.

Waschka, W., Scherer, T., Kim, S. and Wittig, S., 1992. Study of heat transfer and leakage in high rotating stepped labyrinth seals, ISROMAC-4.

Wittig, S., Kim, S., Jakoby, R. and Weissert, I., 1994 Experimental and numerical study of orifice discharge coefficients in high speed rotating disks, ASME 94-GT-142.

Wittig, S., Kim, S., Scherer, T., Jakoby, R. and Weissert, I, 1995. Durchfluß an rotierenden Wellen- und Scheibenbohrungen und Wärmeübergang an rotierenden Wellen, Abschlußbericht, Forschungsvereinigung Verbrennungskraftmaschinen $(F V V)$, Vorhaben Nr. 465 und 536, Heft R 574. 


\section{ait \\ ENERGY MATERIALS}

M A N E Y publishing

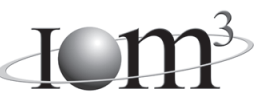

\section{Materials Science \& Engineering for Energy Systems}

Maney Publishing on behalf of the Institute of Materials, Minerals and Mining

The Institute of Materials, Minerals \& Mining

Economic and environmental factors are creating ever greater pressures for the efficient generation, transmission and use of energy. Materials developments are crucial to progress in all these areas: to innovation in design; to extending lifetime and maintenance intervals; and to successful operation in more demanding environments. Drawing together the broad community with interests in these areas, Energy Materials addresses materials needs in future energy generation, transmission, utilisation, conservation and storage. The journal covers thermal generation and gas turbines; renewable power (wind, wave, tidal, hydro, solar and geothermal); fuel cells (low and high temperature); materials issues relevant to biomass and biotechnology; nuclear power generation (fission and fusion); hydrogen generation and storage in the context of the 'hydrogen economy'; and the transmission and storage of the energy produced.

As well as publishing high-quality peer-reviewed research, Energy Materials promotes discussion of issues common to all sectors, through commissioned reviews and commentaries. The journal includes coverage of energy economics and policy, and broader social issues, since the political and legislative context influence research and investment decisions.

\section{CALL FOR PAPERS}

Contributions to the journal should be submitted online at http://ema.edmgr.com

To view the Notes for Contributors please visit: www.maney.co.uk/journals/notes/ema

Upon publication in 2006, this journal will be available via the Ingenta Connect journals service. To view free sample content online visit: www.ingentaconnect.com/content/maney

For further information please contact:

Maney Publishing UK

Tel: +44 (0)113 2497481 Fax: +44 (0)1132486983 Email: subscriptions@maney.co.uk

or

Maney Publishing North America

Tel (toll free): 8662975154 Fax: 6173546875 Email: maney@maneyusa.com

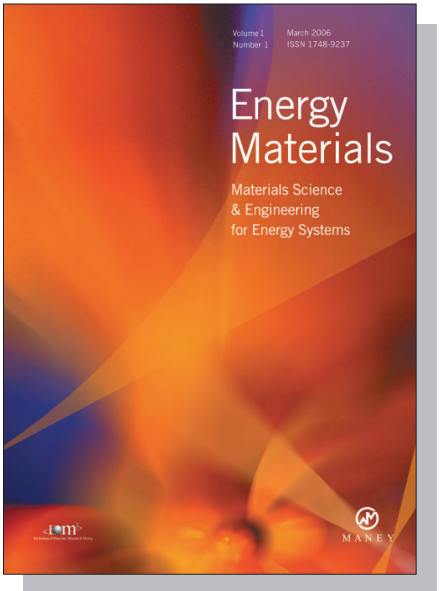

EDITORS

Dr Fujio Abe

NIMS, Japan

Dr John Hald, IPL-MPT, Technical University of Denmark, Denmark

Dr R Viswanathan, EPRI, USA

\section{SUBSCRIPTION INFORMATION}

Volume 1 (2006), 4 issues per year

Print ISSN: 1748-9237 Online ISSN: 1748-9245

Individual rate: $£ 76.00 / U S \$ 141.00$

Institutional rate: $£ 235.00 /$ US $\$ 435.00$

Online-only institutional rate: $£ 199.00 / U S \$ 367.00$

For special $\mathrm{IOM}^{3}$ member rates please email

subscriptions@maney.co.uk

\section{For further information or to subscribe online please visit www.maney.co.uk}



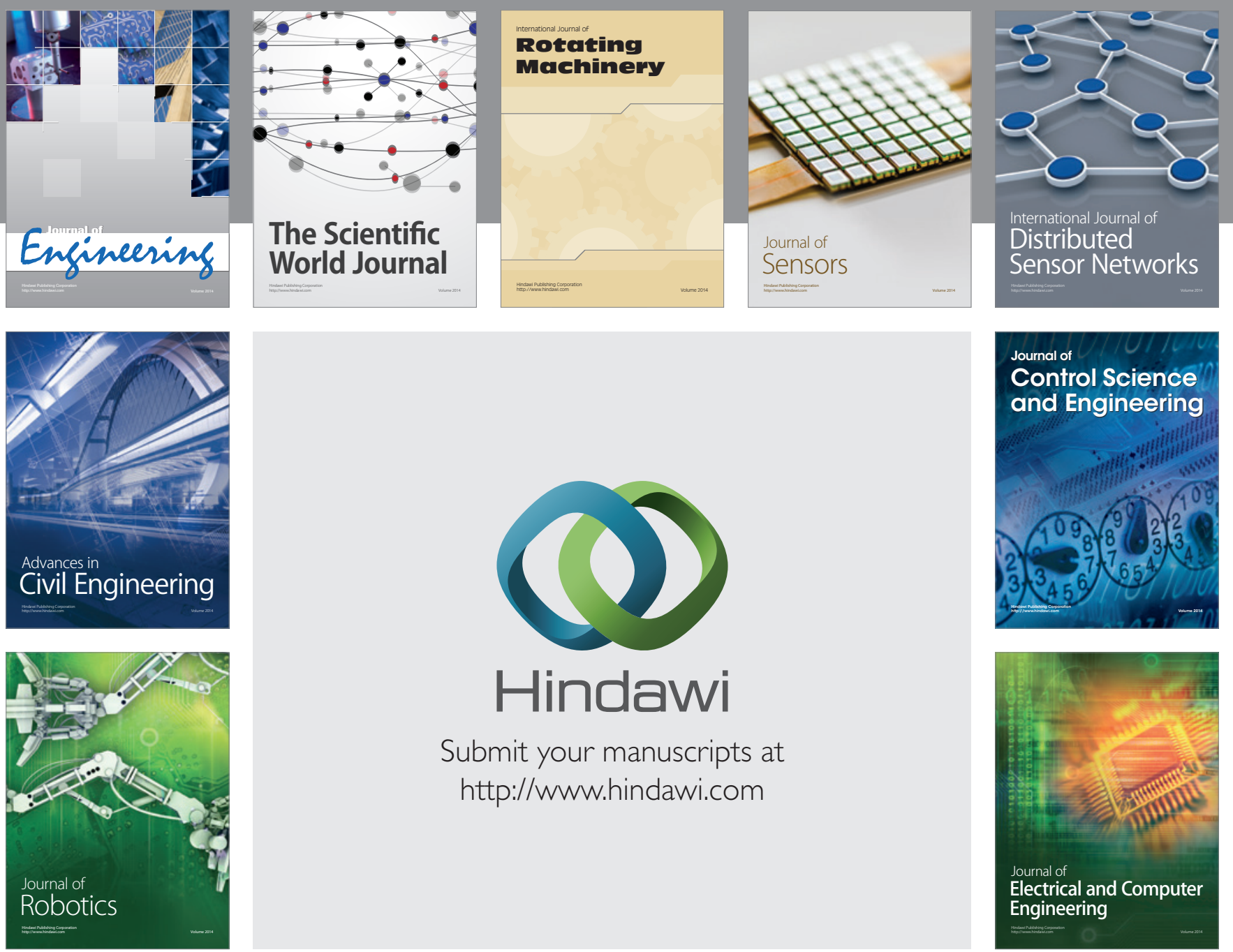

Submit your manuscripts at

http://www.hindawi.com
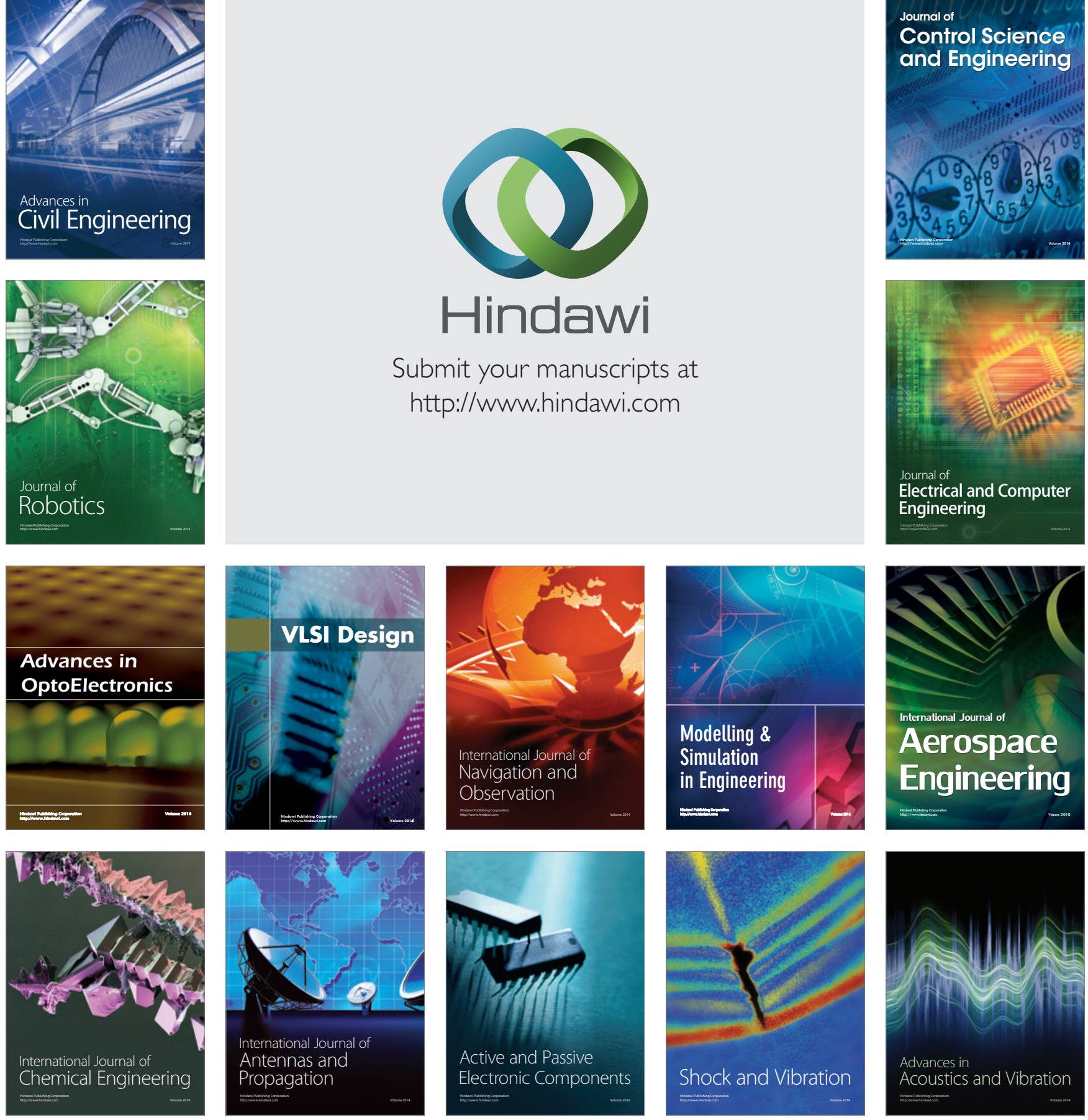